\title{
Weathering the Storm: Measuring Household Willingness-to-Pay for Risk-Reduction in Post-Katrina New Orleans
}

\author{
Craig E. Landry* \\ Associate Professor, Department of Economics \\ Assistant Director, Center for Natural Hazards Research \\ East Carolina University, Greenville, NC 27858 \\ landryc@ecu.edu; 252-328-6383 \\ Paul Hindsley \\ Assistant Professor, Department of Environmental Studies \\ Eckerd College, St. Petersburg, FL 33711 \\ Okmyung Bin \\ Associate Professor, Department of Economics \\ East Carolina University, Greenville, NC 27858 \\ Jamie B. Kruse \\ Professor, Department of Economics \\ Director, Center for Natural Hazards Research \\ East Carolina University, Greenville, NC 27858 \\ John C. Whitehead \\ Professor, Department of Economics \\ Appalachian State University, Boone, NC 28608 \\ and \\ Kenneth R. Wilson \\ Professor, Department of Sociology \\ East Carolina University, Greenville, NC 27858
}

\footnotetext{
* Corresponding author; thanks are due to participants of Katrina Research Symposium (organized by Tulane University) and seminar participants at Mississippi State University, Department of Agricultural Economics. This research was supported by the National Science Foundation - Small Grants for Exploratory Research (award \# SES-0554987).
} 


\title{
Weathering the Storm: Measuring Household Willingness-to-Pay for Risk-Reduction in Post-Katrina New Orleans
}

\begin{abstract}
The city of New Orleans suffered extensive damage as a result of Hurricane Katrina. Katrina overwhelmed the natural and built environment, inundating the city. As rebuilding proceeds, decisions on investment in protective measures will include the choice of lines of defense and the storm severity that design criteria should meet. An exhaustive list of protective measures has been studied in planning documents such as the Louisiana Coastal Protection and Restoration Technical Report (2009), with public comment solicited in town hall meetings. In this study we employ a different approach to examine public sentiment towards the selection and investment in protective measures. Our study utilizes a stated choice experiment with a stratified sample to investigate individuals' willingness-to-pay for rebuilding New Orleans' man-made storm defenses, restoring natural storm protection, and improving evacuation options through a modernized transportation system. We target residents of the New Orleans metropolitan area as well as other US citizens. Our results indicate that individuals are willing-to-pay for increased storm protection for New Orleans, but the allocation of these resources differs among residents of the New Orleans metro area and other US citizens.
\end{abstract}

Key words: storm surge mitigation, conjoint analysis, willingness to pay, Hurricane Katrina, flood control, stated choice, rebuilding New Orleans, recovery

JEL: H43, Q51, R53 


\section{Weathering the Storm: Measuring Household Willingness-to-Pay for Risk-Reduction in Post-Katrina New Orleans}

\section{Introduction}

Hurricane Katrina made landfall on the Louisiana-Mississippi border of the Gulf Coast August 29th of 2005, leaving behind widespread devastation on the Alabama, Mississippi, and Louisiana coasts. Although the eyewall of Katrina did not pass directly over New Orleans, wind driven waves and storm surge breached several points in the levee system, demonstrating that the city was ill equipped for a storm of Katrina's magnitude. Insufficient artificial and natural storm protection, in conjunction with New Orleans' highly vulnerable physical and human geography, contributed to devastation throughout the city.

Media images of the disaster in New Orleans were burned in the social consciousness of the American public. At the time of the storm, New Orleans was a city of immense poverty and racial inequality. ${ }^{1}$ To make matters worse, many of New Orleans' most vulnerable citizens lived in low lying areas most susceptible to flooding. Although evacuation orders had been made before Katrina's landfall, many New Orleans residents were unable or unwilling to leave. According to the 2000 US Census, $35 \%$ of African American households in New Orleans had no vehicle. Government officials at the city, state, and federal levels had not only failed to protect New Orleans adequately from this type of event; they were also unprepared for the emergency management challenges leading up to the storm and in its aftermath. The confluence of poor

\footnotetext{
${ }^{1}$ According to the 2000 Census, $31 \%$ of African American families in New Orleans fell below the poverty line as compared to $5 \%$ of white families. Also, according to 2005 U.S. Department of Housing and Urban Development estimates, $100 \%$ of public housing residents in New Orleans were African American. Of these individuals, $29 \%$ had resided in public housing for between 10 to 20 years and $31 \%$ had resided in public housing for over 20 years.
} 
preparation and the vulnerability of the city and many of its people, led to one of the most costly natural disasters in U.S. history.

In the aftermath of Hurricane Katrina, the public has been forced to make difficult decisions concerning how to rebuild. The geographic and social vulnerabilities of New Orleans contribute to the complexity of determining how government will allocate public funds for rebuilding. There was an estimated $\$ 10$ billion in damage to roads, bridges and the utility system in New Orleans alone. In Orleans Parish, 134,344 housing units (71\% of the housing stock) were damaged, making rebuilding no small feat. New Orleans borders water on three sides, and much of the city lies below sea level, essentially creating a bowl between Lake Pontchartrain and the Mississippi River. When the levees fail, as they did after Katrina, this bowl can fill up, leaving much of the city underwater. New Orleans relies heavily on a system of levees and pumps which hold back Lake Pontchartrain and the Mississippi River and remove water when it enters the bowl. ${ }^{2}$ Clear evidence of this vulnerability is the 27 major flooding disasters that have occurred in New Orleans over its roughly 300 year history (Kates, Colten, Laska, and Leatherman 2006).

During Katrina, over $80 \%$ of New Orleans was flooded, largely as a result of failed levees. A preliminary analysis by the University of California at Berkeley and the American Society of Civil Engineers determined that these levees failed before they were overtopped, indicating design failure (Seed et al. 2006). The potential damage from a major hurricane had received considerable attention from the media and academics prior

\footnotetext{
${ }^{2}$ The state's levee system was founded in the Louisiana constitution, which created local levee and drainage districts to build and maintain levees. Since Katrina, class action suits have been brought against the Orleans Levee District, the Lake Borgne Basin Levee district, the East Jefferson Levee District and their respective Boards of Commissioners and the US Army Corps of Engineers.
} 
to Katrina. ${ }^{3}$ Unfortunately, there was insufficient political will to heed these warnings and protect the city in time. The existing system did not perform up to its projected Category 3 storm-protection standard.

There are a number of reasons as to why federal, state, and local governments failed to adequately fund levees and other flood protection measures. The U.S. Army Corps of Engineers faced cost increases and design changes stemming from technical issues that limited their ability to fund new construction projects. A Corps fact sheet from May 2005 stated that the appropriated funds for fiscal year 2005 were insufficient to cover new construction projects, including levee enlargement to enhance protection in the New Orleans Metropolitan area. In addition, socio-political issues, including environmental concerns, legal challenges, and local opposition to some aspects of the flood management plan, complicated initiation and completion of some projects (US GAO 2005). The contentious environment surrounding levee maintenance and augmentation combined with the high price tag limited initiative to address flood hazard in New Orleans, not only for President Bush, but also previous administrations.

Kunreuther and Pauly (2006) refer to this phenomenon as the not in my term of office (NIMTO) syndrome.

Aside from man-made structures, natural coastal features such as wetlands and barrier islands provide additional storm protection for coastal regions. Previous estimates from Hurricane Andrew suggest that a linear kilometer of coastal marsh can reduce storm surge by roughly $7.9 \mathrm{~cm}$ (Lovelace 1994). While flooding from Katrina was largely the

\footnotetext{
${ }^{3}$ Between June 23-27, 2005 the New Orleans Times-Picayune ran a series entitled "Washing Away" that was critical of federal, state, and local government flood risk management in south Louisiana. The vulnerability of New Orleans was also mentioned in the US Commission for Ocean Policy, as well as in a Scientific American piece titled "Drowning New Orleans" (Fischetti 2001).
} 
result of failed levees, degraded coastal wetlands played a significant role in the disaster. Louisiana has experienced significant losses of coastal wetlands, stemming from individual and government actions at various levels within the Mississippi River basin. Kousky and Zeckhauser (2006) term spatial externalities associated with losses in ecosystem services as JARing actions (Jeopardized Assets that are Remote). The construction of levees, dams, and canals in the Mississippi River basin since the $19^{\text {th }}$ century has significantly changed sediment transport in the system. Alterations in sediment transport have starved wetlands (Turner 1999). In addition, land subsidence (either natural or due to hydrocarbon extraction) and rising sea levels threaten low lying coastal areas (Morton et al. 2002). Decreased sediment flow and resource extraction have imposed external costs on New Orleans and other Gulf coast cities in the form of a degraded natural environment and reduced storm protection.

Kousky and Zeckhauser (2006) attribute the challenges of addressing JARing actions to the difficulties associated with assigning responsibility, as well as the large number of injured and injuring parties. In the case of post-Katrina New Orleans, reduced storm defenses were the result of a combination of choices made by businesses and residents across the Mississippi River basin as well as the federal government over many decades. Ironically, many of the initiatives that ultimately degraded Louisiana's coastal marshes were designed to reduce flood risk. Development levees reduce the risk of river flooding by keeping rising waters in the river channel. By prohibiting river flooding, however, coastal marshes are deprived of sediment and become degraded, ultimately raising the risk of storm surge and flooding. Many of these type of flood reduction efforts were undertaken by parties throughout the Mississippi River basin with little 
awareness or regard to the potential impacts on coastal marshes and individuals downstream. The externalities of river channelization thus occur at a broad spatial scale and can involve significant time lags.

In addition to natural and man-made flood protection, transit and highway infrastructure play a key role in evaluating the vulnerability of coastal populations. The capacity and resilience of transit and highway infrastructure affect how successfully transit can be used in emergency evacuation and disaster response. In a special report, the Transportation Research Board recommended that "Federal funding should be provided for the development of regional evacuation plans that include transit and other public transportation providers." Further, public transit fills a unique role in providing a mode of evacuation for populations that are transit-dependent and may require special assistance. In spite of this, current evacuation plans do not fully reflect this important role.

Public transportation serves populations with relatively high proportions of racial and ethnic minorities, persons with low incomes, persons with limited English proficiency and persons living in households without vehicles. In a report commissioned by the Federal Transit Administration's Office of Civil Rights, it was concluded that in 20 metropolitan regions under study, "with some exceptions, the agencies reviewed in this study have taken limited steps towards involving populations with specific mobility needs in emergency preparedness, planning ... or coordinating with other agencies to meet the specific needs of these populations in an emergency."

The Louisiana Coastal Protection and Restoration Plan (LACPR, 2009) and Mississippi Coastal Improvements Program (MsCIP, 2009) were created in response to a 
U.S. Congressional directive to develop plans for hurricane risk reduction and coastal restoration. The LACPR Plan Formulation Atlas considered measures that could be combined to form an exhaustive 200 million restoration and protection policy alternatives. The final technical report presents four to six alternatives for each of five planning units - hurricane and storm surge resistant levees, protective coastal landscapes, livable communities, cultural resources, and level of storm and flood risk. Our study investigates a general and limited set of options. We examine individuals' willingnessto-pay to reduce flood risk in New Orleans through application of a stated choice experiment. In so doing we offer a different perspective to LACPR in a fairly simple framework. We provide a measure of the public will (both national and local) to protect human and physical capital in this vulnerable location. The choice experiment focuses on hypothetical projects which propose lines of defense in the form of coastal restoration and Category 5 levees, as well as modernizing existing transportation networks in New Orleans. Through the application of a stratified sampling procedure, we investigate rebuilding preferences for individuals in the New Orleans metropolitan area and U.S. tax payers in general.

Our results suggest that levee flood protection designed to withstand a category 5 storm is the most salient rebuilding feature. New Orleans metro area residents are willing to pay $\$ 301$ per household for category 5 levee protection, while the average U.S. household is willing to pay more, an estimated $\$ 509$. We speculate that this difference could reflect higher average income for the U.S. population relative to New Orleans residents, assuming flood protection is a normal good. Results of the combined model 
indicate an average willingness-to-pay (WTP) of $\$ 449$ per U.S. household for upgrading New Orleans levee system to withstand a Category 5 storm.

Surprisingly, WTP for coastal restoration was not statistically significant for the New Orleans or U.S. samples, but the combined model indicates an overall average economic value of $\$ 103$ per household. We find evidence of significant variability in the utility attributable to coastal restoration across the U.S. and combined samples. A latent class model reveals that individuals that view coastal restoration as an important part of rebuilding New Orleans and have higher income are willing to pay \$214 for coastal restoration, while those that do not see coastal restoration as important and have lower income are not willing to pay.

New Orleans metro area residents are willing to pay an estimated $\$ 137$ per household for modernized transportation in the New Orleans metro area, while the average U.S. household is not willing to pay for this. Again, the latent class model reveals some differences in economic value across groups, with higher income U.S. households that view coastal restoration as important harboring a negative WTP for improvements in transportation. We speculate that this reflects a concern that improved infrastructure will encourage additional development in hazard prone areas like New Orleans. Nonetheless, results of the combined model indicate an average WTP of $\$ 103$ per U.S. household for modernizing New Orleans' transportation infrastructure.

\section{Preferences for Rebuilding New Orleans}

The main purpose of this paper is to evaluate individual preferences for the reconstruction of New Orleans. The rebuilding plans constitute a series of local public 
goods; we estimate individual willingness to pay for these public goods. Since many decisions have yet to be made on restoring New Orleans, we employ hypothetical choice experiments (CE) to assess preferences for rebuilding. CE are a stated preference method that can be used to value the characteristics of rebuilding projects. In a CE, subjects are asked to express a preference over several alternatives. The alternatives vary in the levels of attributes offered, and can include a status quo or "no choice" option. The attributes associated with each option and their levels are chosen by the researcher to address the valuation question at hand. By observing respondents' choices over a number of choice sets, we can learn about the tradeoffs individuals are willing to make in terms of a rebuilding plan for New Orleans.

Our principal sample is composed of New Orleans metropolitan area households - the primary beneficiaries of rebuilding efforts. We employ a random digit dialing survey that utilizes paired comparisons - status quo rebuilding plan versus an alternative that can exhibit improvements in flood control, coastal restoration, and/or transportation infrastructure. The paired comparison approach was deemed necessary because visual aids were difficult to employ with a telephone survey. By focusing on status quo versus an alternative in each choice set, we minimize the amount of information that respondents must process, as the status quo was constant across all choice sets. We utilize an experimental design that allows us to maximize statistical performance while maintaining task simplicity. In addition to the New Orleans subjects, we also gathered choice data from a sample of U.S. households.

\section{Experimental Design}


Our choice experiment investigates rebuilding options using four primary attributes: i) levee augmentation, ii) coastal restoration, iii) transportation system improvements, and iv) a funding mechanism in the form of a one-time increase in federal income tax payments. As indicated in table 1, each program attribute has two levels, while the tax attribute has four levels. The initial level of each program attribute is described as the status quo level in order to facilitate the pair wise choice design. Similar to previous work in the environmental literature (Adamowicz et al. 1994, 1998; Layton and Brown 2000; McGonagle and Swallow 2005; Ladenburg and Olsen 2008), the choice experiment focuses on preferences for public goods - in our case, this is rebuilding or improving public works - rather than preferences for private goods, such as funds for rebuilding private property (which would primarily benefit individual households and businesses). We focus on public projects which decrease existing vulnerabilities (levee augmentation and coastal restoration) or enhance evacuation possibilities (improvements in transportation infrastructure). Examples of conjoint choice sets can be found in section B of the Appendix.

Respondents were given a choice between two levels of flood protection. The status quo option was to ensure that all levees were capable of withstanding the wind, waves, and storm surge that would accompany a Category 3 storm. The alternative option would fortify all levees to be capable of withstanding the wind, wave action, and storm surge consistent with a Category 5 hurricane. By congressional mandate, the LACPR offers multiple planning options capable of providing this level of protection. As such, we chose to focus on this level of storm protection, which will provide a sense of the magnitude of the maximum benefits that storm protection could provide. This 
estimate would be an upper bound on other levels of storm protection, all else being equal.

The choice sets include an option for restoration of Louisiana's coastal wetlands. The status quo option is no coastal restoration, and the alternative is to invest in restoring coastal wetlands. Improvements in coastal wetlands would provide additional protection against hurricane force winds and storm surge. In addition, restoring coastal wetlands would provide for additional environmental benefits, such as fisheries habitat and other ecosystem services. These additional benefits were not noted in the survey, but we suspect that many coastal residents are aware of these additional benefits.

The survey also asked respondents to consider improvements in New Orleans' transportation infrastructure. The status quo option entails limited bus service, street cars, and conventional roads. The alternative is modernized transportation infrastructure that includes expanded bus and light rail (e.g. street car) service and improved road networks. The modernized transportation system would provide for improved transit through the city on a day-to-day basis and would enhance the ability of citizens to evacuate in the event of a hurricane.

The payment vehicle was a compulsory, one-time increase in federal income tax payments for all U.S. households. The status quo was provided at zero additional cost, while the tax payment associated with the alternative varied at $\$ 50, \$ 150, \$ 300$, or $\$ 450$ per household. The survey explicitly states that all money raised by this one-time tax would go directly to rebuilding projects in New Orleans and restoration projects in coastal Louisiana. 
Hypothetical bias is a potential limitation of our CE research method. This bias can arise within a stated preference framework due to the hypothetical nature of the exercise; lacking real incentives for choice, subjects may not be sufficiently motivated to expend cognitive effort to search their preferences. Evidence of hypothetical bias in $\mathrm{CE}$ is mixed (Carlsson and Martinsson 2001; Lusk and Schroeder 2004; Johansson-Stenman and Svedsäter 2008). Lusk and Schroeder (2004) find suggestive evidence that CE are capable of producing unbiased estimates of marginal willingness-to-pay (WTP), while there may be bias in estimation of total WTP. There is some evidence that hypothetical bias can be attenuated through application of a "cheap talk" script, which focuses respondent attention on the phenomenon of bias and encourages them to respond as if the exercise were real (Carlsson, Frykblom and Lagerkvist 2005; List, Sinha, and Taylor 2006). We, thus, employ a variant of cheap talk that is similar to the original language in Cummings and Taylor (1999), but shortened to fit within the context of a telephone survey and changed to reflect differences in the nature of the good being valued. The cheap talk script is included in section A of the Appendix.

With our proposed attributes, a full factorial design has 32 choice sets; fully efficient designs for linear models can be constructed with 8 or 16 choice sets. We chose 16 choice sets, which represents a fractional factorial design from which main effects can be estimated. The choice of a fractional factorial design partly reflects the fact that there were dominated options in the full factorial (e.g., status quo conditions at zero vs. positive price); we did not allow for dominated options. We follow Huber and Zwerina (1996) in constructing a linear experimental design that is orthogonal (levels of each attribute vary independently of one another) and balanced (levels of each attribute appear 
with equal frequency), and one for which overlap of attributes within each choice set is minimized and utility is balanced so that expected probabilities are equal across choices. We employ SAS Macros $\% M k t E x$ and $\%$ ChoiceEff to design a fully efficient $(100 \%$ A and D efficiency for a linear model) fractional factorial design of 16 pair wise choice sets (Kuhfeld 2005). In all choice sets, the status quo is offered against an alternative plan that has at least one improvement in program attributes.

As our econometric model is non-linear, however, we cannot claim that our design is in fact fully efficient (which would require advance knowledge of unknown parameters). Huber and Zwerina (1996) claim that using linear designs for choice experiments is a reasonable approach in situations for which no prior knowledge of parameter estimates is available. In order to lessen the burden on subjects, we utilize a blocked design of the 16 choice sets, employing four choice sets per respondent. The $\% M k t B l o c k$ SAS Macro was used to efficiently partition our 16 choice sets into 4 blocks of 4 choice sets. An example of one of the blocks is included in section B of the Appendix. The sequencing of the choice sets within each block was alternated across respondents in order to control for order effects, producing a total of 16 choice sets -4 blocks of 4 choice sets with 4 sequences.

\section{Survey Questionnaire and Administration}

Our survey targeted two populations, residents of the New Orleans Metropolitan Statistical Area (MSA) and U.S. residents not in the New Orleans MSA. Each survey had three primary sections, and we estimated it would take between 10 and 15 minutes to administer. The first section of the New Orleans survey elicits information concerning 
the respondent's family attachment to New Orleans, whether the respondent experienced Hurricane Katrina, and whether this event and the aftermath would influence their decision to stay in the area. The first section includes a series of Likert-scale questions designed to assess the subjects' perceptions of various attributes of the rebuilding plan, including the importance of crime control, housing availability, job creation, flood protection, coastal wetland restoration, improved transportation, and cultural preservation. For the U.S. survey, the first section gauges individuals' familiarity and experience with New Orleans, in addition to the assessment of perceptions of the importance of rebuilding factors.

The second section of the survey administers the choice experiment. Our blocked experimental design offered four choices to each respondent, with subjects choosing either the status quo at $\$ 0$ additional federal taxes per household or an alternative scenario that offers improvements in the rebuilding plan for one-time payment of additional federal taxes for each U.S. household. Subjects were instructed to treat each choice set as if it were an independent referendum that should be considered in isolation from the other choices. In each survey, we precede the four hypothetical choices with a cheap-talk script (see section A of the Appendix). The third part of the survey elicits information on socio-demographic factors, including gender, ethnicity, whether the respondent considers her/himself Latino or Cajun, level of education, employment status, age, income and household size.

\section{Data}


Our sample was collected via a stratified random digit dial of telephone numbers in the New Orleans MSA and other U.S. households. The survey was administered between May 2007 and June 2008 by individuals in East Carolina University’s Sociology Research Lab. Successful contact rates were low for the New Orleans MSA; this likely reflects displaced households. The final dataset includes information from 128 households in the New Orleans MSA and 220 U.S. households not in the New Orleans vicinity; the corresponding raw response rates are $128 / 500=25.6 \%$ and $220 / 500=44 \%$, respectively. Once contact was established with the household, however, the cooperation rates were $43 \%$ for the New Orleans MSA and $62 \%$ the U.S. Due to incomplete information, only 120 households in the New Orleans MSA and 217 U.S. households not in the New Orleans vicinity are used in the choice models.

In an effort to address potential response bias, we develop a weighting scheme to adjust data to match characteristics from the 2006 American Community Survey (U.S. Census Bureau). Our inverse probability weights are based on observable demographic factors - gender, race, Latino status, education level, marital status, and income. Table 2 depicts the weighted and un-weighted descriptive statistics for the New Orleans and U.S. strata. We estimate choice models for both strata, and combine the strata in order to estimate a single model, applying weights so that the results reflect observable population characteristics.

The average New Orleans respondent had been living in the metropolitan area 41 years, and $76 \%$ of households contacted have at least one set of parents from the New Orleans area. Eighty-one percent were in New Orleans when Hurricane Katrina struck. Thirty-two percent of households have considered leaving New Orleans in the wake of 
the disaster, with $22 \%$ indicating they are very likely or somewhat likely to leave. About seven percent of U.S. respondents indicated that they have visited New Orleans, and 15 percent responded that they either visit on a regular basis or plan to visit in the future. Eleven percent of U.S. respondents indicated that they have friends or family in the New Orleans area.

Tables 3-5 report results on individual perceptions of the importance of various factors in the rebuilding plan for the New Orleans and U.S. samples in the form of a weighted frequency table. Our results indicate that individuals in both samples believe that flood protection is very important, but a higher proportion of individuals in the New Orleans sample feel that both coastal wetland restoration and improved transportation are very important.

\section{Methods}

We utilize the Random Utility Model (RUM) as a theoretical basis for our choice experiment. We assume that individuals choose rebuilding projects for New Orleans which yield the highest level of utility. Individual $n$ 's utility associated with a choice $i$ in choice set $t$, denoted $U_{n i t}$, is a function of project characteristics, $x_{n i t}$, and associated cost, $c_{n i t}$. Utility can be decomposed into an observable portion, $V_{n i t}\left(x_{n i t}, c_{n i t} ; \alpha^{*}, \beta^{*}\right)$, and an unobservable portion known only by the subject, $\varepsilon_{n i t}$ :

$$
U_{n i t}=V_{n i t}\left(c_{n i t}, x_{n i t} ; \alpha^{*}, \beta^{*}\right)+\varepsilon_{n i t},
$$

where $\alpha^{*}$ and $\beta^{*}$ are unknown parameters to be estimated. The probability of individual $n$ choosing a project $i$ over other choice $j$ in set $t$, is thus:

$$
P_{n i t}=\operatorname{Pr}\left[V_{n i t}\left(c_{n i t}, x_{n i t} ; \alpha^{*}, \beta^{*}\right)+\varepsilon_{n i t} \geq V_{n j t}\left(c_{n j t}, x_{n j t} ; \alpha^{*}, \beta^{*}\right)+\varepsilon_{n j t}\right] .
$$


We assume the observable portion of utility is additive:

$V_{n i t}\left(c_{n i t}, x_{n i t} ; \alpha^{*}, \beta^{*}\right)=\alpha^{*} c_{n i t}+\beta^{*} x_{n i t}$. Under the assumption that the error terms in [2], $\varepsilon_{n i t}$, are i.i.d. extreme value variates for all $n, i$, and $t$, the choice probabilities take the closed-form expression:

$$
P_{n i t}=\frac{\exp \left(\alpha^{*} c_{n i t}+\beta^{*} x_{n i t}\right)}{\sum_{j} \exp \left(\alpha^{*} c_{n j t}+\beta^{*} x_{n j t}\right)},
$$

Under this pooled logit formulation, the multinomial logit (MNL) model can be used to estimate the normalized unknown parameters, $\alpha=\alpha^{*} / \sigma$ and $\beta=\beta^{*} / \sigma$, where $\sigma$ is the scale parameter of the extreme value distribution. It is widely recognized, however, that MNL incorporates taste variation in a potentially restrictive manner, limits substitution patterns, and does not allow for correlation across repeated individual choices. Thus, in our application of RUM, we employ the repeated mixed logit (RXL) model (Herriges and Phaneuf 2002; Train 1999) and the latent class (LC) or finite mixture model (Boxall and Adamowicz 2002; Train 1999), each of which incorporates unobserved individual heterogeneity by allowing the $\alpha$ and/or $\beta$ parameters to vary within the sample. The variability of utility parameters incorporates taste heterogeneity, provides for more complex substitution patterns, and allows correlation across individual choices.

For the RXL model, the $\varepsilon_{n i t}$ are i.i.d. extreme value variates for all $n, i$, and $t$, and the choice probabilities for any period $t$ are conditional on an individual-specific vector $\beta_{n}$. Including an alternative specific constant for the status quo, the conditional choice probabilities are given by: 


$$
\breve{P}_{n i t}(\psi, \alpha, \beta)=\frac{\exp \left(\psi d_{n i t}+\alpha c_{n i t}+\beta x_{n i t}\right)}{\sum_{j} \exp \left(\psi d_{n j t}+\alpha c_{n j t}+\beta x_{n j t}\right)},
$$

where $d_{n j t}=1$ for status quo, zero otherwise. We assume $\beta \sim \phi(\beta \mid \mu, \Omega)$, where $\phi$ is a multivariate normal probability density with mean $\mu$ and covariance matrix $\Omega$. Since our experiment is designed to estimate main effects, we restrict $\Omega$ to be diagonal; covariance parameters would only be identified based on functional form. Since $\varepsilon_{n i t}$ are i.i.d. for all $t$, the conditional probabilities for a series of choices $\boldsymbol{i}=\left\{i_{1}, \ldots i_{\mathrm{T}}\right\}$ is given by the product of [4] across choice occasions:

$$
\breve{P}_{n i}(\psi, \alpha, \beta)=\prod_{t=1}^{T} \frac{\exp \left(\psi d_{n i_{t} t}+\alpha c_{n i_{t} t}+\beta_{n} x_{n i_{t} t}\right)}{\sum_{j} \exp \left(\psi d_{n j_{t} t}+\alpha c_{n j_{t} t}+\beta_{n} x_{n j_{t} t}\right)}
$$

Under the formulation of RXL, the unconditional choice probabilities are:

$$
P_{n i}=\int \breve{P}_{n i}(\psi, \alpha, \beta) \phi(\beta \mid \mu, \Omega) d \beta
$$

The likelihood function is the product of [6] over all individuals in the sample. The means of the $\psi$ and $\alpha$ parameters, as well as the means and variance terms for $\beta$ are recovered from Simulated Maximum Likelihood estimates.

The LC model differs from the RXL in that it incorporates unobserved individual heterogeneity through the use of discrete rather than continuous mixing distributions. In this model, it is hypothesized that individual specific characteristics $\left(s_{n}\right)$ sort individuals into $K$ groups. Each group potentially has different preferences over project choices, so that the probability of [2] conditional on membership in group $k$ is:

$$
\breve{P}_{n i t}^{k}=\frac{\exp \left(\psi^{k} d_{n i t}+\alpha^{k} c_{n i t}+\beta^{k} x_{n i t}\right)}{\sum_{j} \exp \left(\psi^{k} d_{n j t}+\alpha^{k} c_{n j t}+\beta^{k} x_{n j t}\right)} \forall k .
$$


Since the unobserved errors are i.i.d. extreme value across $t$, the conditional probabilities for a series of choices $\boldsymbol{i}=\left\{i_{1}, \ldots i_{\mathrm{T}}\right\}$ by type $k$ is given by the product of [7] across choice occasions:

$$
\breve{P}_{n \mathrm{i}}^{k}(\psi, \alpha, \beta)=\prod_{t=1}^{T} \breve{P}_{n i t}^{k}
$$

Group membership is unknown to the researcher. The conditional choice probabilities in [8] are weighted by logit probabilities for class membership, that take the form:

$$
\pi_{n k}\left(\delta^{k}\right)=\frac{\exp \left(\delta^{k} s_{n}\right)}{\sum_{h \in K} \exp \left(\delta^{h} s_{n}\right)},
$$

where the vector $s_{n}$ contains demographic variables that influence class membership according to unknown parameters $\delta^{k}$. Identification requires that parameters for one $k \in K$ are normalized to zero. The unconditional probability for a series of choices by individual $n$ is obtained by a weighted sum of [8] over the $k$ groups, where the weights are given by [9]:

$$
P_{n \mathrm{i}}=\sum_{k \in K} \pi_{n k}\left(\delta^{k}\right) \times \breve{P}_{n i}^{k}(\psi, \alpha, \beta)
$$

The parameters of model [10] are estimated by maximum likelihood.

We use compensating variation (CV) to measure the incremental welfare change, also known as marginal willingness to pay (MWTP), associated with program attributes for rebuilding New Orleans. Conditional on $\beta_{n}, \mathrm{CV}$ for a rebuilding program attribute is defined as:

$$
C V_{n}=\frac{\Delta x\left(\beta_{n}\right)}{-\alpha},
$$


for each element of the vector $x$. Given the discrete nature of program attributes, $\Delta x=1$.

For the RXL model, equation [11] is simulated for all $n$ respondents by taking $R$ draws from the posterior distribution of $\beta$, calculating $\mathrm{CV}$ and averaging across the $R$ calculations. For the LC model, equation [11] is calculated for each of the $k$ segments (replacing $\beta_{n}$ with $\beta^{k}$ ). Mean CV can be calculated as the weighted average across segments, where the weights are given by [9]. The Krinksy-Robb procedure (1986) is used to produce standard errors of CV. Krinsky-Robb is a parametric bootstrap method which takes random draws from the multivariate normal distribution of parameters utilizing information from the vector of estimated parameters and the variance-covariance matrix. In our application we take 10,000 random draws in order to develop both $90 \%$ and $95 \%$ confidence intervals of MWTP.

\section{Results}

The random utility models (RUMs) are estimated using Matlab and NLOGIT (Greene 2007). ${ }^{4}$ We estimate three models using the RXL estimator, corresponding with New Orleans, U.S., and combined datasets. Each model includes dummy variables for projects with category 5 levees, coastal restoration, and modernized transportation system. For the U.S. and combined models, all of these parameters are assumed to be drawn from a normal distribution with diagonal covariance matrix. For the New Orleans sample, the coefficient for the Category 5 levee and modernized transportation are assumed fixed; estimated standard deviations for these parameters under the assumption

\footnotetext{
${ }^{4}$ The Mixed Logit was estimated using code written by H. Allen Klaiber for the "Micro-Econometrics In and Out of Markets: A Second Training Workshop on Micro-Econometrics in Environmental Economics." This workshop was developed and funded by the Center for Environmental and Resource Economic Policy (CEnREP) at North Carolina State University and the US Environmental Protection Agency.
} 
of normality were not statistically significant. ${ }^{5}$ The coefficients for the alternative specific constant representing the status quo option and the tax variable are assumed fixed. Models were estimated using Maximum Simulated Likelihood based on 1000 Halton draws. ${ }^{6}$ Table 6 presents the parameter estimates for RXL choice models. In each of the three models, the constant representing the status quo is not statistically significant. As anticipated, the coefficient on the one-time tax increase is negative and statistically significant at $0.1 \%$ chance of a type I error in each model. For each model, the coefficient representing category 5 levees is positive, implying that individuals prefer projects that implement the maximum level of storm protection. Each coefficient representing category 5 levee protection is statistically significant at the $1 \%$ level. Among project attributes, category 5 levee protection has the largest coefficient, indicating that the average individual believes this project attribute is important relative to other program attributes. Under the assumption of normality, the standard deviation for this coefficient suggests that most individuals exhibit positive preferences for this attribute, but significant preference heterogeneity does exist for U.S. and combined models.

In allowing for a random parameter for coastal restoration, the standard deviation was found to be statistically insignificant for the New Orleans model. Employing a fixed coefficient, the mean utility effect for coastal restoration in the New Orleans models is statistically significant (at the $10 \%$ level), and we estimate a positive parameter. Results for U.S. and combined models suggest that utility values for coastal restoration encompass both negative and positive values. The mean coefficient for coastal

\footnotetext{
${ }^{5}$ A likelihood ratio test supports this restriction.

${ }^{6}$ See Train (2003) for a discussion of utilizing Halton sequences to draw from densities in mixed logit models.
} 
restoration is not statistically significant in these models, but the standard deviations are statistically significant at the $1 \%$ level. We interpret these results as indicating that some individuals in the broader population value coastal restoration while others perceive it as something that should not be funded through general taxation.

The coefficient for modern transportation is positive in each model, but statistically significant only for the New Orleans (5\% level) and combined (10\% level) estimates. As variability in the random parameter was not statistically significant, the New Orleans model is estimated with a fixed parameter. The estimated mean effects for New Orleans and combined are positive, as expected. In the Combined and U.S. samples the standard deviations for the distribution of coefficients for modern transportation are statistically significant at the $10 \%$ and $5 \%$ level, respectively. Much like coastal restoration, results from the combined and U.S. samples indicate that some individuals favor rebuilding projects with modernized transportation while others favor projects without it.

In an effort to investigate determinants of preference heterogeneity within our samples, we also estimated LC models for both the New Orleans and U.S. samples. While these efforts were inconclusive for the New Orleans sample, the approach did reveal potential sources of variation in preferences among U.S. residents. We focus on a similar specification for the LC model, with a status quo alternative-specific constant, a project tax or cost variable, and indicator variables for category 5 levees, coastal restoration, and modernized transportation systems. Socio-demographic variables defining the finite mixture probabilities are comprised of household income and the likert 
scale response indicating the importance of coastal wetland restoration. Table 7 presents the results of the latent class model for the U.S. sample. ${ }^{7}$

For the LC model, respondents are endogenously divided into $K=2$ groups, with posterior probabilities suggesting that roughly $35 \%$ of the sample falls into the first group and the remaining $65 \%$ in the second group. The class membership probability parameters indicate that the first group views coastal wetland restoration as less important than the second group. The negative sign on the income variable also indicates that the first group is represented by lower income households. The status quo variable is positive and statistically significant for group 1 , indicating that individuals with less concern over coastal restoration and lower income are more likely to vote for no improvements in the rebuilding plan for New Orleans. For each group, the coefficient for category 5 levees is positive and statistically significant at the $1 \%$ level, implying that individuals in both groups prefer projects that employ the maximum level of storm protection. Individuals in the second group respond positively to projects that include coastal restoration, while choices in the first group were not affected by coastal restoration. The coefficient for modern transportation was positive for both groups, but not statistically significant. Lastly, the coefficient on tax is negative and statistically significant at the $1 \%$ level for each group, as expected. The negative impact of cost, however, is four times larger for those in the first group.

Table 8 presents marginal willingness-to-pay (MWTP) estimates for rebuilding attributes which mitigate future risks to New Orleans and its citizens. Figures $1-3$ depict the confidence intervals of MWTP for rebuilding attributes in the different samples. Our estimates indicate that the average individual in the New Orleans sample is

\footnotetext{
${ }^{7}$ Results for the Combined model are very similar.
} 
willing to pay $\$ 301$ for category 5 levee protection versus $\$ 509$ for the average individual in the U.S. sample. The average individual in the combined sample is willing-to-pay $\$ 449$ for category 5 levees. The confidence intervals, estimated with the Krinsky-Robb procedure, indicate that all welfare estimates for Category 5 levee protection are statistically significant at the $1 \%$ level. The latent class model allows us to examine welfare estimates for discrete groups of U.S. residents. The first group, identified as likely to include individuals that view coastal restoration as less important in the rebuilding plan and individuals with lower income, is associated with a willingness to pay of $\$ 433$ for category 5 levees. An average individual from the second group (counterpart to the first group) is willing to pay $\$ 514$ for category 5 levees. The difference between these two welfare estimates for the LC model is not statistically significant. As indicated in figure 1, all estimates (except New Orleans) exhibit significant overlap and similar central tendancies.

Turning to coastal restoration values, we do not obtain statistically significant measures of MWTP for the New Orleans and U.S. samples for the RXL model. In the former case, this result likely reflects the low level of significance for the fixed coastal restoration parameter, while in the latter it reflects wide variability in this random parameter. The average individual in the combined model is willing to pay $\$ 103$ for coastal restoration, and this estimate is significant at the $5 \%$ level. Estimates from the LC model indicate an average individual from the second group in the U.S. sample is willing to pay \$214 for coastal restoration. Figure 2 indicates that only the estimates associated with the combined RXL model and group 2 for the LC model have distributions with sufficient mass above zero. 
Lastly, we find that the average individual in the New Orleans sample is willing to pay $\$ 137$ for modernized transportation (significant at the $10 \%$ level), while MWTP for the U.S. sample is not statistically significant in the RXL results. Households in the combined sample are willing to pay $\$ 103$ for modernized transportation (significant at the $10 \%$ level). With the LC model, MWTP is positive but insignificant for group one, but negative and statistically significant for group two! The average person in group $2-$ more likely to include higher income households and individuals that view coastal restoration as important - has a negative MWTP value of $-\$ 93.45$ (significant at the $5 \%$ level). These distributions of MWTP are depicted in figure 3.

\section{Discussion and Conclusions}

Following the extensive devastation unleashed by Hurricane Katrina, policymakers must make difficult decisions about how to rebuild storm defenses in New Orleans and along the Gulf Coast. Increasing costs of protection and maintenance and evolving vulnerabilities due to climate change and human intervention in natural coastal systems have exacerbated hazards in southern Louisiana. These tendencies combined with historical social and economic inequality and a lack of political will to address vulnerabilities contributed to the Katrina disaster. In the wake of the storm, comprehensive coastal protection plans for Louisiana and Mississippi have been proposed and are in the vetting process at this time. The plans propose multiple lines of defense that include shoring up man-made flood defenses and restoring natural defenses in the region. But, how do the affected parties, both at the local and national level, value investments in public goods designed to reduce vulnerabilities along the Gulf Coast? 
Employing choice experiments via a random digit dialing telephone survey, we produce estimates of economic value for public projects that reduce risk from severe storms. Our experiment offers improvements in levee flood protection, coastal restoration, and improvements in transportation infrastructure. Each alternative improvement scenario is associated with higher one-time payment of federal taxes for all U.S. households. These improvements are valued in pair wise comparisons with status quo conditions, and thus our estimates represent marginal willingness-to-pay for riskreducing projects. Each subject evaluates four pair wise choice sets of the total 16 choice sets, which were designed using efficient algorithms for linear models. The choice experiment was implemented as a referendum with majority rules provision, and subjects were instructed to treat each choice as independent of other choices.

In general, respondents find traditional engineered flood protection structures to be the most salient and valued line of defense. The local and national sentiment indicates that improved levee protection is a valuable public investment. Coastal restoration garners some support but not to the degree that built flood protection systems received. Lastly, improved transportation systems are supported but not as strongly as levee improvement and coastal restoration. Results of the repeated mixed logit model indicate that households in the New Orleans metro area are willing to pay $\$ 301$ per household for category 5 levee protection and $\$ 137$ per household to modernize the New Orleans metropolitan transportation system. In addition to households' values for Category 5 levee protection, which primarily reflects a form of hazard mitigation, benefits from modernized transportation also represent an improvement to quality of life via better dayto-day transportation options. Estimates of value for coastal restoration for New Orleans 
resident are not statistically significant. Aggregating over all New Orleans tax-paying households, estimated economic value for Category 5 flood protection is approximately \$118 million ( 95\% confidence interval: \$54 million - \$181 million). ${ }^{8}$ The aggregate economic value of modernized transportation infrastructure for tax-paying New Orleans households is $\$ 54$ million (90\% confidence interval: $\$ 7$ million - $\$ 100$ million).

We also present results for a sample of U.S. households that were offered the opportunity to vote in the same choice experiment. Surprisingly, U.S. residents are willing to pay $\$ 509$ per household for Category 5 levees in New Orleans. This mean estimated economic value exceeds New Orleans residents' mean MWTP by 69 percent. Comparing opinions on flood protection, 84 percent of U.S. respondents feel it is 'very important' to protect New Orleans from floods, compared to 98 percent of New Orleans residents. Thus, this economic value could reflect a true preference for flood protection in this vulnerable and culturally distinct location. The difference could reflect a higher income for the U.S. population relative to New Orleans residents, assuming flood protection is a normal good.

Accounting for preference heterogeneity via the repeated mixed logit model, we do not find a statistically significant economic value for U.S. households that can be attributed to coastal restoration in South Louisiana. Further investigation, however, utilizing the latent class model allows us to endogenously divide the U.S. sample into two distinct groups based on observable factors. The first group is more likely to include lower income households that do not view coastal wetland restoration as important, while the second group is characterized by those with higher incomes and who place greater

\footnotetext{
${ }^{8}$ According to the 2005-2007 American Community Survey 3-Year Estimates, there are 392,659 households in the New Orleans MSA.
} 
importance on coastal restoration. Willingness to pay for coastal restoration for the first group is not significantly different from zero, but the average individual in the second group is willing to pay $\$ 214$ for coastal restoration. Members of the first group may be less familiar with coastal wetlands, in general, and unaware of the storm protection provided by coastal marshes. Fifty-two percent of U.S. respondents consider coastal restoration as 'very important', considerably less than the 86 percent of New Orleans residents that express this view. Using posterior probabilities, we estimate that the average likelihood of individuals in our sample belonging to the first group is around $35 \%$.

Lastly, with the repeated mixed logit model, U.S. respondents' willingness-to-pay for improvements in transportation infrastructure is not statistically significant; again, the LC model reveals different results. While we did not find a significant result for group 1, parameters for the second U.S. group exhibited a negative and statistically significant willingness-to-pay for modernized transportation. This result may indicate that these types of individuals disapprove of development in high risk areas and do not want to create an incentive for expanded redevelopment in the form of modernized transportation. Public services, such as utilities and public transportation, act as de facto land use policy since they provide access to more locations. This, in effect, can create incentives for development because a larger proportion of the population can access more remote areas. Without modern transportation, people may be dissuaded from developing in remote or high risk locations.

Combining the two samples and reweighting for representation at the national level and to correct for response bias based on observable factors, we produce tentative 
estimates of economic value for risk-reduction in New Orleans. Under the assumption that this sample is a reasonable approximation of national preferences, the average U.S. household is willing to pay $\$ 449$ for upgrading New Orleans levee system to withstand a Category 5 storm, and the average WTP for coastal restoration is $\$ 103$ per household. The average U.S. household is WTP $\$ 103$ for modernized transportation. Aggregating over all U.S. tax-paying households, economic values for rebuilding New Orleans are: approximately $\$ 50$ billion (95\% confidence interval: $\$ 29$ billion $-\$ 71$ billion) for Category 5 flood protection in New Orleans, $\$ 12$ billion (95\% confidence interval: $\$ 2$ billion - \$21 billion) for coastal restoration, and \$12 billion ( $90 \%$ confidence interval: $\$ 0.3$ billion - \$21 billion) for modernized transportation. ${ }^{9}$ These estimates could provide valuable information for policymakers as they analyze risk-reducing projects for New Orleans and southern Louisiana.

\section{References}

Adamowicz, W., J. Louviere, and M. Williams. 1994. "Combining Revealed and Stated Preference Measures for Valuing Environmental Amenities," Journal of Environmental Economics and Management 26(3): 271-292.

Adamowicz, W., P. Boxall, M. Williams, and J. Louviere. 1998. "Stated Preference Approaches for Measuring Passive Use Values: Choice Experiments and Contingent Valuation" American Journal of Agricultural Economics 80(1): 64-75.

Bierlaire, M. 2003. "BIOGEME: A free package for the estimation of discrete choice models" Proceedings of the 3rd Swiss Transportation Research Conference: Ascona, Switzerland.

Bierlaire, M. 2008. “An introduction to BIOGEME Version 1.7” biogeme.epfl.ch

\footnotetext{
${ }^{9}$ According to the 2005-2007 American Community Survey 3-Year Estimates, there are 111,609,629 households in the US.
} 
Boxall, P., and W. Adamowicz. 2002. "Understanding Heterogeneous Preferences in Random Utility Models: A Latent Class Approach." Environmental and Resource Economics 23: 421-446.

Carlsson, F. and P. Martinsson. 2001. "Do Hypothetical and Actual Marginal Willingness to Pay Differ in Choice Experiments?" Journal of Environmental Economics and Management 41: 179-192.

Carlsson, F., P. Frykblom, and C. J. Lagerkvist. 2005. "Using Cheap Talk as a Test of Validity in Choice Experiments" Economics Letters. 89(2): 147-152.

Cummings, R.G. and L.O. Taylor. 1999. "Unbiased Value Estimates for Environmental Goods: Cheap Talk Design for the Contingent Valuation Method" American Economic Review 89: 649-65.

Federal Transit Administration. 2007. "Transportation Equity in Emergencies: A Review of the Practices of State Departments of Transportation, Metropolitan Planning Organizations, and Transit Agencies in 20 Metropolitan Areas," \# FTA-PA-26-80012007 Prepared for Federal Transit Administration, U.S. Department of Transportation http://www.fta.dot.gov/civilrights/civil_rights_6343.html accessed May, 2008.

Greene, William H. 2007. NLOGIT 4.0 Reference Guide, Econometric Software, Plainview, NY.

Herriges, J.A., and D.J. Phaneuf. 2002. "Inducing Patterns of Correlation and Substitution in Repeated Logit Models of Recreation Demand" American Journal of Agricultural Economics. 84(4): 1076 - 1090.

Hole, A.R.. 2007. “A Comparison of Approaches to Estimating Confidence Intervals for Willingness to Pay Measures" Health Economics. 16(8): 827-40

Huber, J. and K. Zwerina. 1996. "The Importance of Utility Balance in Choice Designs" Journal of Marketing Research 33: 307-317.

Johansson-Stenman, O. and H. Svedsäter. 2008. "Measuring Hypothetical Bias in Choice Experiments: The Importance of Cognitive Consistency" The B.E. Journal of Economic Analysis and Policy 8, Article 41.

Kates, R.W., C.E. Colten, S. Laska, and S.P. Leatherman. 2006. "Reconstruction of New Orleans after Hurricane Katrina: A research perspective" Proceedings of the National Academy of Sciences of the United States of America 103(40): 14653-14660.

Kousky, C, E.F. Luttmer, and R.J. Zeckhauser. 2006. "Private investment and government protection" Journal of Risk and Uncertainty. 33: 73-100. 
Kousky, C, and R.J. Zeckhauser. 2006. "JARing Actions that Fuel Floods", In On Risk and Disaster: Lessons from Hurricane Katrina. R.J. Daniels, D.F. Kettl, and H. Kunreuther eds. Philadelphia: University of Pennsylvania Press.

Krinsky, I. and A. Robb. 1986. "On Approximating the Statistical Properties of Elasticities." The Review of Economics and Statistics. 86: 715-19.

Kuhfeld, W. 2005. "Marketing Research Methods in SAS: Experimental Design, Choice, Conjoint, and Graphical Techniques" SAS 9.1 version. http://support.sas.com/techsup/technote/ts722title.pdf

Kunreuther, H. and M. Pauly. 2004. 'Neglecting Disaster: Why Don't People Insure Against Large Losses?" Journal of Risk and Uncertainty. 28: 5-21.

Kunreuther, H. and M. Pauly. 2006. "Rules rather than discretion: Lessons from Hurricane Katrina" Journal of Risk and Uncertainty. 33: 101-116.

LACPR Louisiana Coastal Protection and Restoration Draft Final Technical Report March 2009 U.S. Army Corp of Engineers, New Orleans District, Mississippi Valley Division http://lacpr.usace.army.mil/default.aspx?p=LACPR_Draft Technical_Report accessed April 2009.

Ladenburg, J. and S.B. Olsen. 2008. "Gender-specific Starting Point Bias in Choice Experiments: Evidence from an Empirical Study" Journal of Environmental Economics and Management 56(3): 275-285.

Layton, D.F. and G. Brown. 2000. "Heterogeneous Preferences Regarding Global Climate Change" The Review of Economics and Statistics 82(4): 616-624

Lovelace, J. K. 1994. "Storm-tide Elevations Produced by Hurricane Andrew along the Louisiana Coast, August 25-27, 1992” Open File Report 94-371, U.S. Geological Survey, Baton Rouge, LA.

List, J.A., P. Sinha, and M.H. Taylor. 2006. "Using Choice Experiments to Value NonMarket Goods and Services" Advances in Economic Analysis and Policy, 6(2): 1-37.

Lusk, J. and T. Schroeder. 2004. "Are Choice Experiments Incentive Compatible? A Test with Quality Differentiated Beef-Steaks" American Journal of Agricultural Economics 85: 840-856.

McGonagle, M.P. and S.K. Swallow. 2005. "Open Space and Public Access: A Contingent Choice Application to Coastal Preservation" Land Economics 81(4): 477-495.

MsCIP Mississippi Coastal Improvements Program Draft Technical Report Februrary 2009 U.S. Army Corp of Engineers, Mobile District 
http:/lacpr.usace.army.mil/Report/DTR/Draft\%20LACPR\%20Technical\%20Report\%20 Mar\%2009.pdf accessed April 2009.

Morton, R.A., N.A. Buster, and M.D. Krohn. 2002. "Subsurface Controls on Historical Subsidence Rates and Associated Wetland Loss in Southcentral Louisiana" Transactions Gulf Coast Association of Geological Societies. 52: 767-778.

Seed, R.B., R.G. Bea, R.I. Abdelmalak, A.F. Athanasopoulos, G.P. Boutwell, J.D. Bray, J.L. Briaud, C. Cheung, C. Cobos-Roa, J. Cohen-Waeber, B.D. Collins, L. Ehrensing, D. Farber, M. Hanemann, L.F. Harder, K.S. Inkabi, A.M. Kammerer, D. Karadeniz, R.E. Kayen, R.E.S. Moss, J. Nicks, S. Nimmala, J. M. Pestana, J. Porter, K. Rhee, M.F. Riemer, K. Roberts, J.D. Rogers, R. Storesund, A.V. Govindasamy, X. Vera-Grunauer, J.E. Wartman, C.M. Watkins, E. Wenk Jr., and S.C. Yim. 2006. "Investigation of the Performance of the New Orleans Flood Protection Systems in Hurricane Katrina on August 29, 2005" University of California, Berkeley, vols 1-2. http://www.ce.berkeley.edu/ new orleans/

Train, K. 2003. Discrete Choice Methods with Simulation. Cambridge University Press: New York.

Transportation Research Board. 2008. "The Role of Transit in Emergency Evacuation," (2008) National Academy of Sciences Transportation Research Board Special Report \#294, ISBN 978-0-309-11333-5 http://onlinepubs.trb.org/Onlinepubs/sr/sr294.pdf accessed May 2008.

Turner, R.E. 1997. "Wetland Loss in the Northern Gulf of Mexico: Multiple Working Hypotheses" Estuaries 20(1): 1-13.

USGS. 1995. "Louisiana Coastal Wetlands: A Resource at Risk" USGS Fact Sheet. U.S. Geologic Survey, Marine and Coastal Geology Program.

http://marine.usgs.gov/fact-sheets/LAwetlands/lawetlands.html 
Table 1: Choice Experiment Design

\begin{tabular}{|c|c|}
\hline Attribute & $\begin{array}{l}\text { Levels } \\
\end{array}$ \\
\hline Levee Protection & $\begin{array}{c}\text { Category Three Storm (status quo) } \\
\text { Category Five Storm }\end{array}$ \\
\hline Coastal Restoration & $\begin{array}{c}\text { No (status quo) } \\
\text { Yes }\end{array}$ \\
\hline Transportation System & $\begin{array}{c}\text { Conventional (status quo) } \\
\text { Modernized }\end{array}$ \\
\hline $\begin{array}{l}\text { One-time Tax Payment } \\
\text { For all U.S. Households }\end{array}$ & $\begin{array}{c}\$ 0(\text { status quo }) \\
\$ 50 \\
\$ 150 \\
\$ 300 \\
\$ 450\end{array}$ \\
\hline
\end{tabular}


Table 2: Descriptive Statistics by Strata.

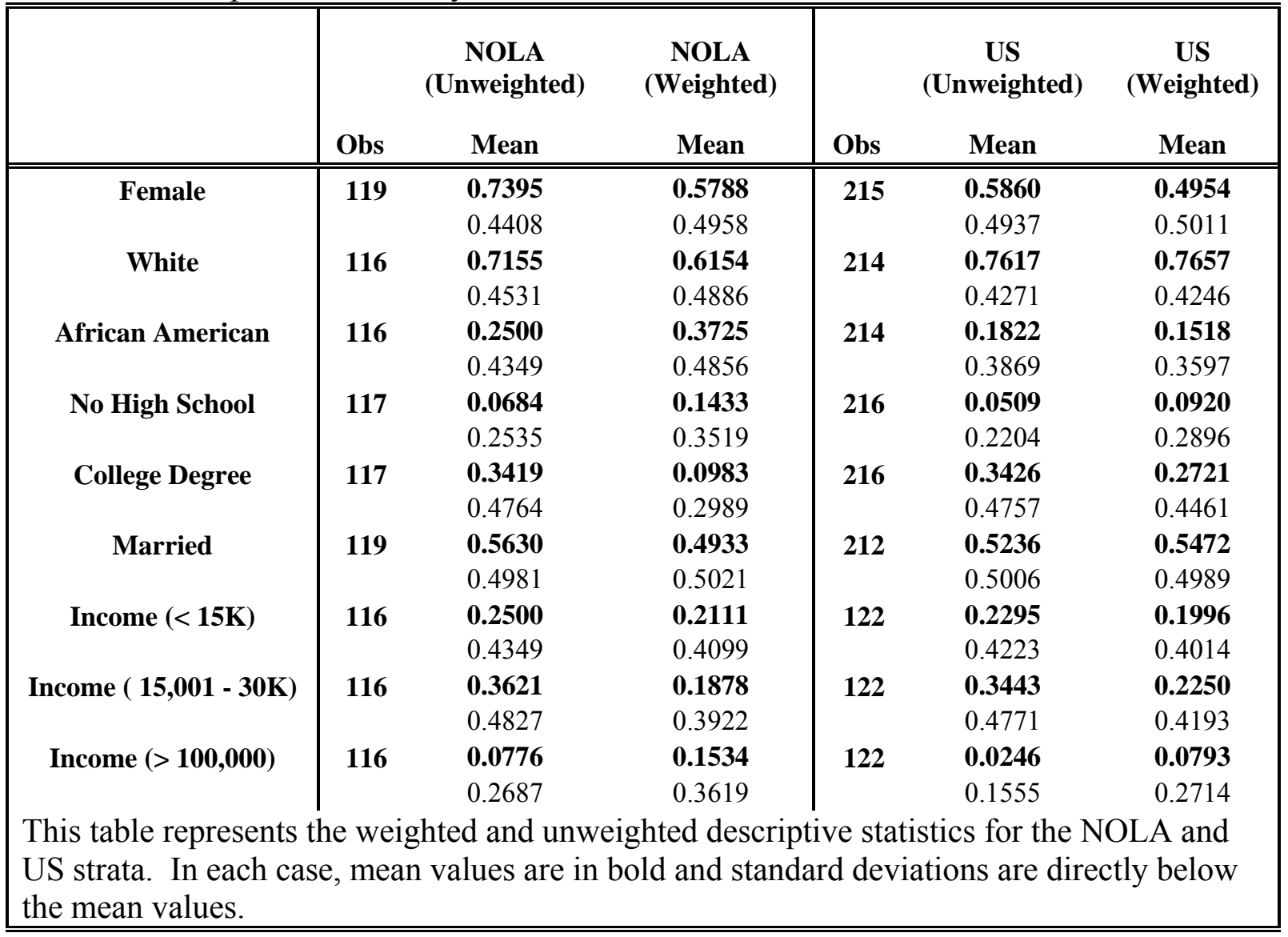


Table 3: Importance of Flood Protection.

\begin{tabular}{lrrrr}
\hline \hline Importance of & US Sample & \multicolumn{3}{c}{ NOLA Sample } \\
Flood Protection & Frequency & Percent & \multicolumn{1}{c}{ Frequency } & Percent \\
\hline \hline Not Important & 7.08860838 & 2.64 & 0 & 0 \\
Somewhat Important & 35.2500004 & 13.12 & 2.04462688 & 1.55 \\
Very Important & 224.599351 & 83.62 & 128.582775 & 97.69 \\
N/A & 1.64643997 & 0.61 & 1 & 0.76 \\
This table reports weighted frequencies to correct for non-response. & \\
\hline \hline
\end{tabular}

Table 4: Importance of Coastal Wetland Restoration.

\begin{tabular}{|c|c|c|c|c|}
\hline \multirow{2}{*}{$\begin{array}{l}\text { Importance of } \\
\text { Coastal Wetland Restoration }\end{array}$} & \multirow{2}{*}{$\begin{array}{l}\text { US Sample } \\
\text { Frequency }\end{array}$} & \multicolumn{3}{|c|}{ NOLA Sample } \\
\hline & & Percent & Frequency & Percent \\
\hline Not Important & 34.5087342 & 12.85 & 5.36724436 & 4.08 \\
\hline Somewhat Important & 94.3255745 & 35.12 & 2.13093932 & 9.22 \\
\hline Very Important & 139.750091 & 52.03 & 113.129218 & 85.95 \\
\hline N/A & 0 & 0 & 1 & 0.76 \\
\hline
\end{tabular}

Table 5: Importance of Improved Transportation.

\begin{tabular}{lrrrr}
\hline \hline Importance of & US Sample & \multicolumn{3}{c}{ NOLA Sample } \\
Improved Transportation & Frequency & Percent & \multicolumn{1}{c}{ Frequency } & \multicolumn{1}{c}{ Percent } \\
\hline \hline Not Important & 10.8639112 & 4.04 & 4.76848871 & 3.62 \\
Somewhat Important & 109.77255 & 40.87 & 36.0447788 & 27.38 \\
Very Important & 145.81486 & 54.29 & 89.8141345 & 68.23 \\
N/A & 2.13307869 & 0.79 & 1 & 0.76 \\
This table reports weighted frequencies to correct for non-response. & \\
\hline \hline
\end{tabular}


Table 6: Repeated Mixed Logit Models

\begin{tabular}{|c|c|c|c|}
\hline & New Orleans & U.S. & Combined \\
\hline ASC1 & $\begin{array}{c}0.5324 \\
(0.3989)\end{array}$ & $\begin{array}{c}0.3663 \\
(0.4026)\end{array}$ & $\begin{array}{c}0.7076 \\
(0.4028)\end{array}$ \\
\hline Category 5 & $\begin{array}{c}1.3801 * * * \\
(0.2957)\end{array}$ & $\begin{array}{c}3.4436^{* * *} \\
(0.6981)\end{array}$ & $\begin{array}{c}2.9463 * * * \\
(0.5836)\end{array}$ \\
\hline Cat 5 Std Dev & $\begin{array}{l}- \\
-\end{array}$ & $\begin{array}{c}3.3284 * * * \\
(0.7477)\end{array}$ & $\begin{array}{c}2.0667 * * * \\
(0.6571)\end{array}$ \\
\hline Coastal Restoration & $\begin{array}{l}0.5177^{*} \\
(0.3088)\end{array}$ & $\begin{array}{c}0.5845 \\
(0.3682)\end{array}$ & $\begin{array}{c}0.6755 \\
(0.4562)\end{array}$ \\
\hline CR Std Dev & $\begin{array}{c}1.6057 * * * \\
(0.5096)\end{array}$ & $\begin{array}{c}2.4609 * * * \\
(0.6770)\end{array}$ & $\begin{array}{c}2.6503 * * * \\
(0.7274)\end{array}$ \\
\hline Modern Transportation & $\begin{array}{c}0.6295^{* *} \\
(0.2766)\end{array}$ & $\begin{array}{c}0.5507 \\
(0.3420)\end{array}$ & $\begin{array}{l}0.6778^{*} \\
(0.3495)\end{array}$ \\
\hline MT Std Dev & & $\begin{array}{c}1.5446^{* * *} \\
(0.6650)\end{array}$ & $\begin{array}{l}1.3564^{*} \\
(0.7155)\end{array}$ \\
\hline Tax & $\begin{array}{c}-0.0046^{* * *} \\
(0.0007) \\
\end{array}$ & $\begin{array}{c}-0.0068 * * * \\
(0.0014) \\
\end{array}$ & $\begin{array}{c}-0.0066^{* * *} \\
(0.0014) \\
\end{array}$ \\
\hline Individuals & 120 & 217 & 336 \\
\hline Observations & 480 & 868 & 1347 \\
\hline Null lnL & -497.355 & -765.094 & -1775.89 \\
\hline $\ln \mathrm{L}$ & -345.7521 & -465.5882 & -1523.98 \\
\hline Halton Draws & 1000 & 1000 & 1000 \\
\hline \multicolumn{4}{|c|}{$\begin{array}{l}\text { Standard errors are in parentheses. Mixing distribution assume normality. } * * * \\
\text { indicates statistical significance for } 1 \text { percent chance of type I error; } * * \text { indicates } \\
\text { statistical significance at } 5 \text { percent, and * indicates statistical significance at } 10 \\
\text { percent. }\end{array}$} \\
\hline
\end{tabular}


Table 7: Latent Class Model: U.S. Sample

\begin{tabular}{|c|c|c|}
\hline & Group 1 & Group 2 \\
\hline ASC1 & $1.441 * *$ & -0.0736 \\
\hline & $(0.623)$ & $(. .1541)$ \\
\hline Category 5 & $3.799 * * *$ & $1.014 * * *$ \\
\hline & $(1.176)$ & $(0.111)$ \\
\hline Coastal Restoration & -0.220 & $0.421 * * *$ \\
\hline & $(0.873)$ & $(0.138)$ \\
\hline Modern & $0.990 * *$ & $-0.184 * *$ \\
\hline & $(0 . .461)$ & $(0.075)$ \\
\hline Tax & $-0.0088 * * *$ & $-0.002 * * *$ \\
\hline & $(0.0022)$ & $(0.0004)$ \\
\hline \multicolumn{3}{|c|}{ Class Probability Parameters } \\
\hline Constant & $\begin{array}{c}4.881 * * * \\
(1.176)\end{array}$ & 0 \\
\hline $\begin{array}{l}\text { Coastal Wetland } \\
\text { Importance }\end{array}$ & $\begin{array}{c}-32.558 * * * \\
(3.266)\end{array}$ & 0 \\
\hline Income & $\begin{array}{c}-0.057 * * * \\
(0.0166)\end{array}$ & 0 \\
\hline Individuals & \multicolumn{2}{|c|}{217} \\
\hline Observations & \multicolumn{2}{|c|}{868} \\
\hline Null LL & \multicolumn{2}{|c|}{-598.8808} \\
\hline $\mathbf{L L}$ & \multicolumn{2}{|c|}{-479.6496} \\
\hline Rho-square & \multicolumn{2}{|c|}{0.199} \\
\hline Iterations & \\
\hline
\end{tabular}

Standard errors are in parentheses. $* * *$ indicates statistical significance for 1 percent chance of type I error;

** indicates statistical significance at 5 percent, and

* indicates statistical significance at10 percent. 
Table 8: Welfare Measures (marginal willingness-to-pay)

\begin{tabular}{|c|c|c|c|c|c|}
\hline & \multicolumn{3}{|c|}{$\begin{array}{c}\text { Repeated Mixed Logit } \\
\text { Models }\end{array}$} & \multicolumn{2}{|c|}{ Latent Class Models } \\
\hline & $\begin{array}{c}\text { Combined } \\
\text { Sample } \\
\end{array}$ & $\begin{array}{c}\text { US } \\
\text { Sample } \\
\end{array}$ & $\begin{array}{l}\text { NOLA } \\
\text { Sample } \\
\end{array}$ & $\begin{array}{l}\text { US Sample } \\
\text { Group 1 } \\
\end{array}$ & $\begin{array}{c}\text { US Sample } \\
\text { Group 2 } \\
\end{array}$ \\
\hline $\begin{array}{c}\text { Category } 5 \\
95 \% \text { CI }\end{array}$ & $\begin{array}{c}\$ 448.75 \\
(\$ 263.16, \$ 634.34)\end{array}$ & $\begin{array}{c}\$ \mathbf{5 0 9 . 1 6} \\
(\$ 329.53, \$ 688.79)\end{array}$ & $\begin{array}{c}\$ 300.87 \\
(\$ 138.54, \$ 463.20)\end{array}$ & $\begin{array}{c}\text { \$432.56 } \\
(\$ 269.12, \$ 596.00)\end{array}$ & $\begin{array}{c}\$ \mathbf{5 1 4 . 3 9} \\
(\$ 291.69, \$ 737.09)\end{array}$ \\
\hline $90 \% \mathrm{CI}$ & $(\$ 292.98, \$ 604.52)$ & $(\$ 358.40, \$ 659.92)$ & $(\$ 164.63, \$ 437.11)$ & $(\$ 295.38, \$ 596.74)$ & $(\$ 327.49, \$ 701.29)$ \\
\hline $\begin{array}{c}\text { Coastal } \\
\text { Restoration } \\
95 \% \text { CI } \\
90 \% \text { CI } \\
\end{array}$ & $\begin{array}{c}\mathbf{\$ 1 0 2 . 8 8} \\
(\$ 18.69, \mathbf{1 8 7 . 1 6 )} \\
(\$ 32.15, \$ 173.62) \\
\end{array}$ & $\begin{array}{c}\$ 86.43 \\
(-\$ 30.31, \$ 203.17) \\
(-\$ 11.55, \$ 184.41)\end{array}$ & $\begin{array}{c}\$ 112.86 \\
(-\$ 28.26, \$ 253.98) \\
(-\$ 5.58, \$ 231.30) \\
\end{array}$ & $\begin{array}{c}-\$ 25.05 \\
(-\$ 266.99, \$ 216.89) \\
(-\$ 228.11, \$ 178.01)\end{array}$ & $\begin{array}{c}\text { \$213.59 } \\
(\$ 0.78, \$ 426.47) \\
(\$ 34.93, \$ 392.25) \\
\end{array}$ \\
\hline $\begin{array}{c}\text { Modernized } \\
\text { Transportation } \\
95 \% \text { CI } \\
90 \% \text { CI } \\
\end{array}$ & $\begin{array}{c}\$ 103.24 \\
(-\$ 16.36, \$ 222.84) \\
(\$ 2.86, \$ 203.62) \\
\end{array}$ & $\begin{array}{c}\$ 81.42 \\
(-\$ 26.83, \$ 189.67) \\
(-\$ 9.43, \$ 172.27) \\
\end{array}$ & $\begin{array}{c}\$ 137.23 \\
(-\$ 4.22, \$ 278.68) \\
(\$ 18.51, \$ 255.95) \\
\end{array}$ & $\begin{array}{c}\$ 112.77 \\
(-\$ 52.91, \$ 278.45) \\
(-\$ 26.28, \$ 251.82) \\
\end{array}$ & $\begin{array}{c}-\$ 93.45 \\
(-\$ 181.57,-\$ 5.33) \\
(-\$ 167.41,-\$ 19.49)\end{array}$ \\
\hline
\end{tabular}

MWTP estimates in bold... 
Figure 1: 95\% Confidence Intervals Depicting MWTP for Category 5 Levee Protection

\section{5\% Confidence Intervals: WTP for Category 5 Levees}

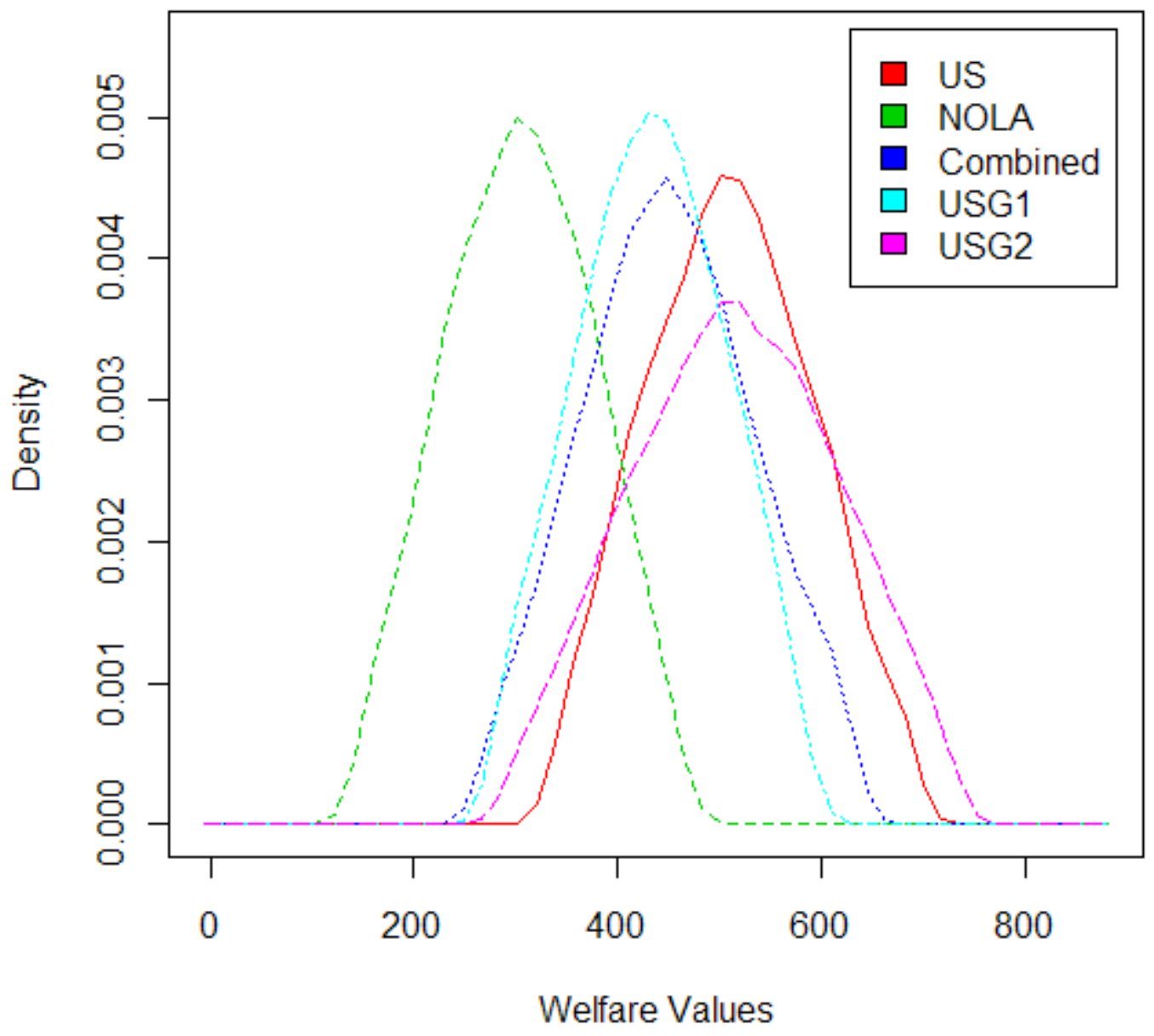


Figure 2: 95\% Confidence Intervals Depicting MWTP for Coastal Restoration

\section{5\% Confidence Intervals: WTP for Coastal Restoration}

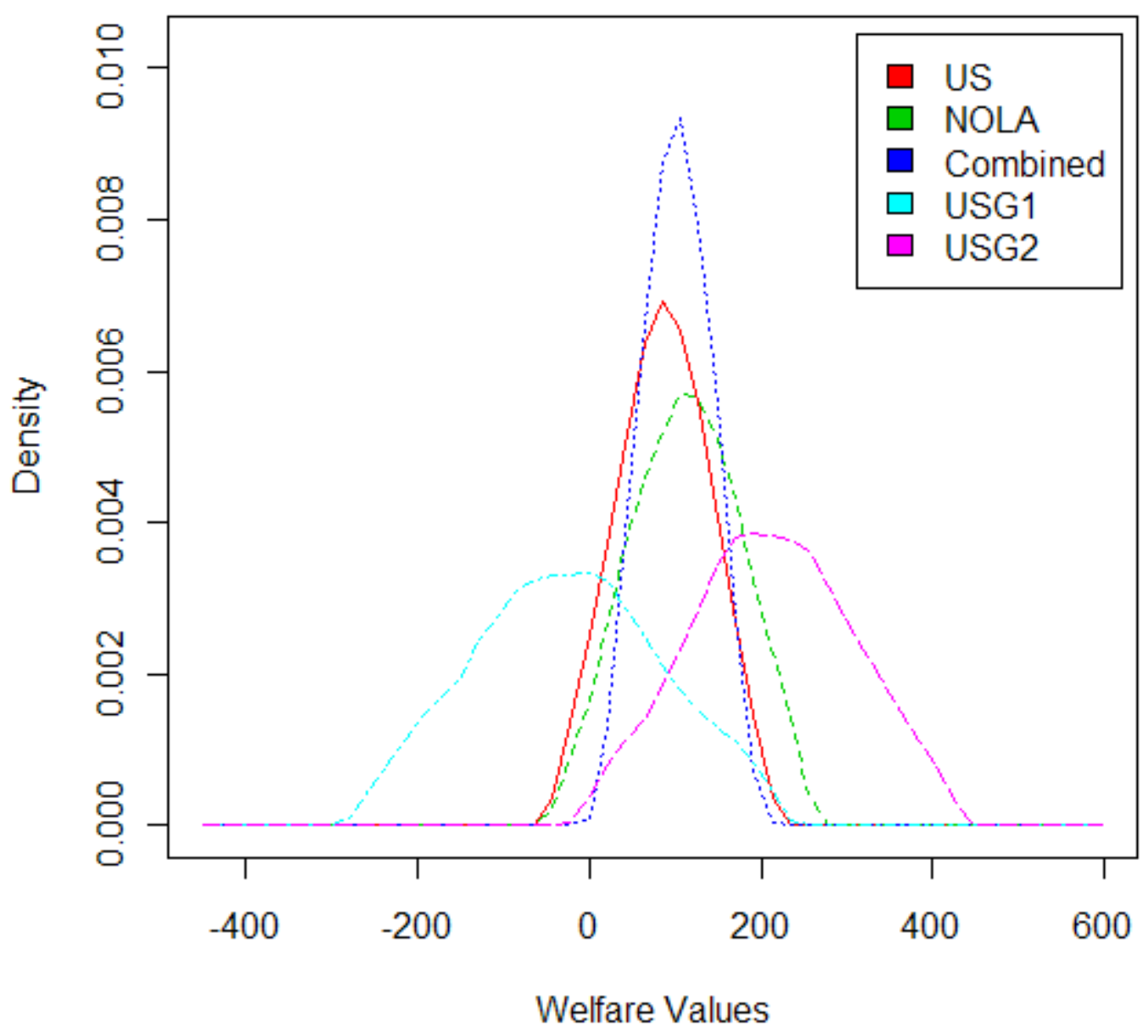


Figure 3: 95\% Confidence Intervals Depicting MWTP for Modern Transportation

\section{5\% Confidence Intervals: WTP for Modernized Transportation}

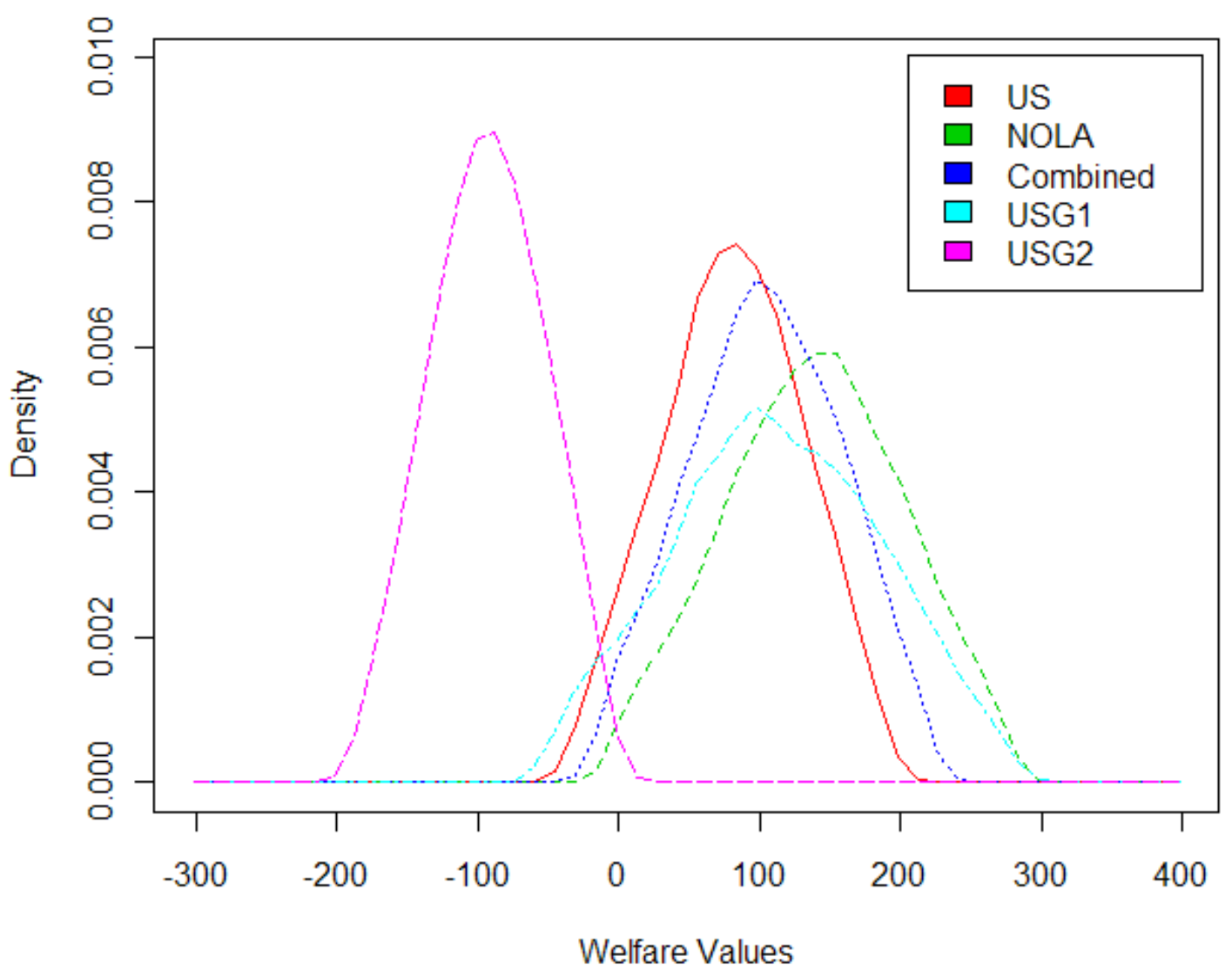




\section{Appendix: A: Cheap Talk Script}

We would now like to ask you about four rebuilding plans for New Orleans. The plans differ in the types of improvements that are made to the city and the cost to taxpayers. Suppose that each of the plans are put up for a vote, you may vote for or against each plan or choose not to vote-majority rules.

Before we get to the vote, consider the following information. In a recent study, groups of people participated in a vote just like the one you are about to participate in. The improvements and costs of the plan for these groups were not real, just as they will not be real for you. No one had to pay money if the vote passed, and most voted for the plan.

Other groups of similar people participated in the same vote, but payment was real and everyone really did have to pay the cost if the vote passed. In these groups most voted against the plan. We call this difference between the way people say they would vote and the way they really vote "bias."

Sometimes when we hear about a vote that involves doing something that is basically good-helping people in need, improving air and water quality, or anything else- our reaction in a hypothetical situation is to think: sure, I would do this. I really would vote to spend the money.

But when the vote is real, and we would actually have to spend our money if it passes, we think a different way. We still would like to see good things happen, but when we are faced with having to spend money, we think about our options; if I spend money on this, that's money I don't have to spend on other things. We vote in a way that takes into account the limited amount of money we have.

I would like for you to think about your votes just like you would think about a real vote, where if enough people vote for the plan, you'd really have to pay and so would everyone else. Please keep this in mind as you answer the four voting questions.

For the purpose of these questions, the current rebuilding plan for New Orleans will be:

- Limited bus service (routes, transfer points, and hours of service buses), limited use of street cars, and conventional road network

- No restoration program for Louisiana's coastal wetlands

- Repair the levee system to withstand a Category 3 hurricane

- You pay $\$ 0$ in additional tax money for one year

We will now give you the opportunity to vote on four separate plans for rebuilding. Each of the four plans differs in the type of improvements that are made and the associated costs. Money to fund the plan would come from a one-time tax on all US households. The tax amount differs due to the nature of the rebuilding plan and because we are uncertain about what the actual costs would be. Assume that all money raised would go directly to rebuilding New Orleans. 
Please consider each plan separately in relation to the current plan, and indicate whether or not you would vote for this plan if the vote were real.

\section{B: Choice Experiment}

Remember, the current plan is (i) limited bus service, street cars, and conventional roads (ii) no restoration of coastal wetlands, (iii) repair the levees to withstand a Category 3 hurricane, and (iv) no additional taxes.

B: Example of Conjoint Choice Set (immediately following above survey text)

\begin{tabular}{|c|c|c|c|c|c|}
\hline Altern & $\begin{array}{c}\text { atives: } \\
\text { Set }\end{array}$ & Transnortation & Coastal restoration & Levee & Tax \\
\hline 1 & 1 & Conventional & YES & Category 3 & $\$ 300$ \\
\hline 1 & 2 & Modern & NO & Category 3 & $\$ 450$ \\
\hline 1 & 3 & Conventional & $\mathrm{NO}$ & Category 5 & $\$ 50$ \\
\hline 1 & 4 & Modern & YES & Category 5 & $\$ 150$ \\
\hline
\end{tabular}

1. Transportation and the levees would be the same as the current plan. This alternative plan proposes to restore coastal wetlands. This plan would cost each US household an extra \$300. Would you vote for the current plan or this new plan?

2. The levees and the coastal wetlands would be the same as the current plan but the new plan would include improvements in the transportation system. This plan would cost each US household an extra \$450. Would you vote for the current plan or this new plan?

3. The transportation and the coastal wetland restoration would be the same as the current plan but the new plan would include improvements in the levees to protect the city against a Category 5 hurricane. This plan would cost each US household an extra \$50. Would you vote for the current plan or this new plan?

4. In this plan, the transportation system would be improved, the coastal wetlands restored and the levees improved to protect the City against a Category 5 hurricane. This plan would cost each US household an extra \$150. Would you vote for the current plan or this new plan? 